\title{
Phytochemical characterization of bioactive compounds on methanolic and ethanolic leaf extracts of Myrciaria sp.
}

\author{
Nathalia F. Naspolini; Mariana P. Seljan; Monica C.P. Santos; Édira C.B.A. \\ Gonçalves*
}

Universidade Federal do Estado do Rio de Janeiro (UNIRIO), Laboratório de Bioativos - Núcleo de Bioquímica Nutricional, Av. Pasteur, $2965^{\circ}$ andar, Bairro Urca - Rio de Janeiro-RJ, Brazil.

Received May 17, 2016. Accepted Jun 27, 2016.

\begin{abstract}
Among the native species of importance in Brazil, jabuticabeira (Myrciaria sp.) is a native fruit tree from several Brazilian regions. Few studies report the chemical constituents of the leaves and its pharmacological and nutraceutical properties. The aim of this study was to identify the phenolic compounds of the methanolic $(\mathrm{MeOH})$ and ethanolic (EtOH) leaf extracts of Myrciaria sp. Phytochemical profile of the extracts was carriedout using High Performance Liquid Chromatography (HPLC) analysis. Antioxidant potential was evaluated by radical scavenging capacity with 2,2-diphenyl-1-picryl-hydrazyl (DPPH) and total phenolics were determined with Folin-Ciocalteau reagent. A total of nine different compounds were identified in the free and bound phenolics extractions: 2,4 dihydroxybenzoic, vanillin, $p$-coumaric, ferulic, sinapinic, rutin, epicatechin, transcaffeic and myricetin. The extracts demonstrated high radical scavenging capacity (MeOH: 1.83 and EtOH: $8.05 \mathrm{mg} / \mathrm{mL}$ ) and high phenolic content (MeOH: 1.15; and EtOH: $1.04 \mathrm{mg} / \mathrm{g}$ dry matter). The wide variability of compounds revealed and the amount of peaks not identified, gives us a background of a potential plant matrix for further investigations in order to develop a nutraceutical agent.
\end{abstract}

Keywords: Myrciaria sp, phenolic compounds, chemical profile, antioxidant capacity.

\section{Introduction}

Brazilian flora has a great diversity of native species, some of them medicinal plants widely used in folk medicine. Considering the variability provided by natural forests and the biological activities already observed in popular experience, this field of research has been increasing in order to characterize bioactive compounds from natural sources. Among the native plant species of importance in Brazil, jabuticabeira (Myrciaria sp.) is a fruit tree that belongs to the Myrtaceae family, which the synonym identification varies between Eugenia cauliflora Miq., Eugenia cauliflora DC., Myrciaria trunciflora Berg, among others. Myrciaria sp. occurs in several Brazilian regions such as northeast, south central and southeast (Henriques et al., 2010).
The fruits of this family occurs generally twice a year and around 30 days after flowering stage. The fruits are globular berries of black color and presents a potential in taste, aroma and external appearance (Henriques et al., 2010).

Regarding the pleasant flavor, the fruits have received attention for containing substances with medicinal characteristics, as well as, some authors already demonstrate that the fruit contain several substances with antioxidant activity, such as ascorbic acid, rutin, quercetin, quercitrin, among others (Borges et al., 2014; Morales et al., 2016).

Besides the fruits, the bark of Myrciaria sp. also appears to contain bioactive compounds. Brazilian people have used it, as a tea made with the bark, to treat diarrhea and skin irritations (Lucena et al., 
2008). Researchers showed on an in vitro trial run, that the bark provided antifungal effect on oral microorganisms (Diniz et al., 2010).

On the other hand, there are few studies concerning the chemical composition of the leaves of Myrciaria sp. Souza-Moreira et al. (2008) demontrated a preliminary standardization of the leaves by histochemical and phytochemical methods. This investigation showed presence of phenols, tannins and alkaloids mainly in the ethanolic extract of the leaves. The same group also demonstrated biological activities as antioxidant and antimicrobial.

In addition, the characterization of the oil constituents, total phenol and tannin contents from Myrciaria sp. leaves was demonstrated by (Duarte et al., 2010), as well as the environmental influence on chemical variability of the plant leaves.

Considering this scenario, few studies address a variety of information about the Myrciaria sp. leaves. Taking into account, the biological activities already demonstrated, the characterization of the chemical constituents of the leaves is a major issue to better understand its pharmacological and nutraceutical properties. The aim of this study was to identify the phenolic compounds in the methanolic $(\mathrm{MeOH})$ and ethanolic (EtOH) leaf extracts of Myrciaria sp., and investigate its radical scavenging capacity and phenolics content.

\section{Material and methods}

\subsection{Plant material}

Myrciaria sp. leaves were collected in Mauá da Serra, Rio de Janeiro, Brazil, in March 2016. Plant material was dried at $40{ }^{\circ} \mathrm{C}$ for 16 hours, crushed and stored at room temperature, protected from light until required for the preparation of extracts.

\subsection{Extraction of phenolic compounds from Myrciaria sp. leaves}

\subsubsection{Free phenolics extraction}

The dry matter was weighed $(0.5 \mathrm{~g})$ in a 50 $\mathrm{mL}$ falcon tube and to each tube was added
$10 \mathrm{~mL}$ of ethanol:water solution (40:60) $(\mathrm{EtOH})$ and methanol:water methanol solution $(80: 20)(\mathrm{MeOH})$ to perform the liquids extractions. The mixture was macerated with an Ultra-Turrax ${ }^{\circledR}$ mixer for $3 \mathrm{~min}$ and homogenized by vortex (Warmnest) for $10 \mathrm{~min}$. Extraction of the homogenized samples was conducted by an incubation under temperature-controlled orbital shaker (KS 4000ic control; IKA, Germany) at $240 \mathrm{rpm}, 60{ }^{\circ} \mathrm{C}$ for 1 hour. After incubation, samples were centrifuged (ST 16R Sorvall Centrifuge; Thermo Scientific, Germany) at $3000 \times \mathrm{g}$ for $5 \mathrm{~min}$ at room temperature. The supernatant was collected and transferred to a rotary evaporator balloon. The described steps was carried out twice and the supernatants were finally combined and dried in a rotary evaporator (Rotavapor R-215, BÜCHI, Switzerland) at $40{ }^{\circ} \mathrm{C}$. The dried residue was reconstituted in $3 \mathrm{~mL}$ methanol:water solution $(3: 97, \mathrm{v} / \mathrm{v})$ and stored at $-20{ }^{\circ} \mathrm{C}$ in screw-capped amber flasks until the moment of analyzes.

\subsubsection{Bound phenolics extraction}

\section{a. Alkaline hydrolyses}

The alkaline hydrolysis was prepared based on the residue from the free phenolics extraction. It was added $6 \mathrm{~mL}$ of Milli-Q water and $2.5 \mathrm{~mL}$ of $\mathrm{NaOH} 10 \mathrm{M}$ into the left precipitate from free phenolics extraction. Samples were homogenized by vortex and the procedure was conducted by an incubation under temperature-controlled orbital shaker at $240 \mathrm{rpm}, 25{ }^{\circ} \mathrm{C}$ for 16 hour. After incubation, the $\mathrm{pH}$ was adjusted to 2 with hydrogen chloride $(\mathrm{HCl})$. Then, it was added $7 \mathrm{~mL}$ of ethyl acetate and homogenized by vortex. Samples were centrifuged at $2500 \times \mathrm{g}$ for 5 $\min$ at $10{ }^{\circ} \mathrm{C}$. The supernatant was collected and transferred to a rotary evaporator balloon. The described steps was carried out twice and the supernatants were combined and dried in a rotary evaporator at $40{ }^{\circ} \mathrm{C}$.

\section{b. Acid hydrolyses}

Based on the residue from the alkaline hydrolyses, it was added $1.5 \mathrm{~mL}$ of $\mathrm{HCl}$ to 
the left precipitate. Samples were incubited in a water bath for $30 \mathrm{~min}$ at $85{ }^{\circ} \mathrm{C}$. It was added $7 \mathrm{~mL}$ of ethyl acetate and homogenized by vortex. Samples were centrifuged at $2500 \times \mathrm{g}$ for $5 \mathrm{~min}$ at $10^{\circ} \mathrm{C}$. The supernatant was collected and transferred to a rotary evaporator balloon. The described steps was carried out twice and the supernatants were combined and dried in a rotary evaporator at $40{ }^{\circ} \mathrm{C}$.

\subsection{Determination of total phenolics}

Total phenolics in the extracts was accessed with Folin-Ciocalteau reagent according to the method from (Singleton et al., 1999), with modifications. Briefly, aliquots of 100,200 and $500 \mu \mathrm{L}$ from the EtOH extract and 50, 100, $200 \mu \mathrm{L}$ from the $\mathrm{MeOH}$ extract of diluted samples (1:100) were added to $2.5 \mathrm{~mL}$ of Folin-Ciocalteau reagent. After $5 \mathrm{~min}$, the volume was adjusted to $5 \mathrm{~mL}$ with the correspondent extractor and it was added $2 \mathrm{~mL}$ of a $4 \%$ sodium carbonate solution and mixed by vortex. The absorbance was measured at $750 \mathrm{~nm}$ using Shimadzu UV-1603 spectrophotometer after 2 hours. A standard curve was plotted using different concentrations of an aqueous solution of gallic acid. The amount of total phenolics compounds was expressed as milligrams of gallic acid equivalents per gram (mg GAE $\mathrm{g}-1)$ of dry matter.

\subsection{Radical scavenging capacity}

Antioxidant activity of the extracts was evaluated using $0.06 \mathrm{mM}$ DPPH (1,1Diphenyl-2-picryl-hydrazyl) in methylalcohol using spectrophotometry at 515 $\mathrm{nm}$. It was added $2.0 \mathrm{~mL}$ of DPPH solution to $100,200,500 \mathrm{uL}$ of diluted samples (1:100), the volume was completed to 2.5 $\mathrm{mL}$ with the correspondent extractor, homogenized in a vortex and kept at dark place for 1 hour. Blank solutions were done replacing DPPH solution to methanol. Anti-radical activity was calculated as discolour percentage of $\mathrm{DPPH}$ according to the equation: $\%=$ (DA-SA/DA). 100 ; where: $\mathrm{DA}=\mathrm{DPPH}$ absorbance; $\mathrm{SA}=$ sample absorbance (Brand-Williams et al., 1995) and the $\mathrm{IC}_{50}$ values were calculated from the dose responses curves. All Assays were performed in duplicate.

\subsection{Identification of phenolic compound profile by HPLC-DAD}

Briefly, samples were diluted in $3 \%$ methanol aqueous solution (5\% dilution), homogenized by vortex, sonicated (Shenzhen Codyson Electrical Co. Ltd.; Shenzhen, China) and filtered through a $0.45 \mu \mathrm{m}$ PTFE membrane filter (Millex; Millipore, Germany) into an ambercolored vials (Allcrom). Samples and standards were analyzed in an HPLC system (Perkin Elmer, Shelton, USA) equipped with a degasser, a column oven and a photodiode array detector (PDA; Perkin Elmer) set at an acquisition data on $260 \mathrm{~nm}, 280 \mathrm{~nm}$ and $320 \mathrm{~nm}$. Phenolic compounds were eluted from a reversedphase C18 column $(5 \mu \mathrm{m} \times 150 \mathrm{~mm}$ x 4.6 mm; Kromasil; Akzobel, Sweden) fitted with a Phenomenex (Torrance, CA, USA) security guard column $(4 \mathrm{x} \quad 3.0 \mathrm{~mm})$ operated at $40{ }^{\circ} \mathrm{C}$ (John and Shahidi, 2010). The mobile phase consisted of $0.3 \%$ $(\mathrm{v} / \mathrm{v})$ formic acid in water (A), methanol (B) and acetonitrile (C), the flow rate was $0.8 \mathrm{ml} / \mathrm{min}$ and the elution gradient is described in Table 1 (Gomes and Torres, 2016). Total run time was $33.2 \mathrm{~min}$ and the injection volume for all samples and standards was $20 \mu \mathrm{L}$.

\section{Table 1}

Mobile phase gradient to phenolic compounds elution from HPLC- DAD reversed-phase C18 Column

\begin{tabular}{cccc}
\hline \multirow{2}{*}{$\begin{array}{c}\text { Time } \\
(\mathrm{min})\end{array}$} & $\begin{array}{c}\text { Formic acid } \\
(0.3 \%)\end{array}$ & Methanol Acetonitrile \\
\cline { 2 - 4 } & 85.0 & 14.5 & 0.5 \\
0.1 & 55.0 & 43.5 & 1.5 \\
7.0 & 5.0 & 93.0 & 2.0 \\
7.0 & 1.0 & 97.0 & 2.0 \\
6.0 & 15.0 & 83.0 & 2.0 \\
3.0 & 85.0 & 14.5 & 0.5 \\
0.1 & 85.0 & 14.5 & 0.5 \\
10.0 & \multicolumn{3}{c}{} \\
\hline
\end{tabular}

All data acquisition and monitoring were carried out at $260 \mathrm{~nm}, 280 \mathrm{~nm}$ and $320 \mathrm{~nm}$ and was performed using the software 
Chromera Data System (Perkin Elmer). Peak identities were determined by comparing the relative retention times and PDA spectra of commercial standards.

\section{Results and discussion}

\subsection{Total phenolic compounds}

Total phenolic contents in the extracts was measured with Folin-Ciocalteau reagent. A little higher phenolic level was found in the $\mathrm{MeOH}$ extract $(1.15 \mathrm{mg} / \mathrm{g}$ dry matter $)$ whereas the EtOH extract presented 1.04 $\mathrm{mg} / \mathrm{g}$ dry matter. These values are compared with values of traditional and exotic fruits (Table 2). It was found similar values in avocado pulp $(1.42 \mathrm{mg} / \mathrm{g}$ of fresh fruit weight) (Wang et al., 2010) and banana pulp ( $2.3 \mathrm{mg} / \mathrm{g}$ of dry fruit weight weight) (Someyaa et al., 2002). On the other hand, much higher amounts was found in the peel of these fruits $(\sim 8.9$ and $9.07 \mathrm{mg} / \mathrm{g}$, respectively). Some other fruits showed greater amounts of total phenolic compounds such as mango (Arbos et al., 2013) and pomegranate (Li et al., 2006) (31.23 and $24.4 \mathrm{mg} / \mathrm{g}$, respectively). It should be considered that all these data were performed separately, and generally, the submission of data varies between different forms of presentation as, $\mathrm{mg}$ of gallic acid equivalents (GAE), catechin equivalent (CE), trolox equivalent (TE), among others. Therefore, the range of comparison becomes restricted.

\subsection{Antioxidant capacity}

The antioxidant capacity of the leaf extracts of Myrciaria sp. was accessed with DPPH reagent, which is based on a decolorization assay that measures the capacity of antioxidants to directly react with DPPH radicals. The highest antioxidant capacity was obtained from the $\mathrm{MeOH}$ extract $\left(1.83 \mathrm{mg} / \mathrm{mL} \mathrm{IC}_{50}\right)$ and the $\mathrm{MeOH}$ extract showed $8.05 \mathrm{mg} / \mathrm{mL} \mathrm{IC}_{50}$ of antioxidant capacity (Table 2). Another authors present the antioxidant capacity of ethanolic extracts (50 and $70 \%$ ) from Myrciaria sp. leaves beyond 90\% (SouzaMoreira et al., 2008), considering data expressed in percentage, we found similar values in the present study, around $93 \%$ for EtOH extract (Table 2). Similar values to the $\mathrm{MeOH}$ extract were found in the peel and kernel of mango extracts, 1.01 and $1.33 \mathrm{mg} / \mathrm{mL} \mathrm{IC} 50$, respectively (Arbos et al., 2013) showing that the Myrciaria sp. leaves has the potential to further investigations.

A H2O:MeOH fraction from Myrciaria sp. fruit presents roughly $0.0062 \mathrm{mg} / \mathrm{mL}$ (Einbond et al., 2004) demonstrating that the fruit has a great antioxidant capacity. The high phenolic compound content founded in the leaves may be responsible for the high antioxidant activity of the extracts (Arbos et al., 2013).

Table 2

Total phenolics content and radical scavenging capacity found in Myrciaria sp. leaves extracts and in different parts of exotic and tropical fruit

\begin{tabular}{lcccl}
\hline Plant/ Fruit extract & $\begin{array}{c}\text { Phenolics } \\
(\mathrm{mg} / \mathrm{g})\end{array}$ & $\begin{array}{c}\text { Antioxidant capacity } \\
(\mathrm{mg} / \mathrm{mL} \mathrm{IC} 50)\end{array}$ & $\begin{array}{c}\text { Antioxidant capacity } \\
(\%)\end{array}$ & Reference \\
\hline MeOH extract & 1.15 & 1.83 & 93.91 & \\
EtOH extract & 1.04 & 8.05 & 78.08 & \\
Mango peel & 66.44 & 1.01 & 88.5 & Arbos et al., 2013 \\
Mango kernel & 31.23 & 1.33 & 69.8 & Arbos et al., 2013 \\
MeOH fraction of Myrciaria & - & 0.0062 & - & Einbond et al., 2004 \\
sp fruit & & - & - & Wang et al., 2010 \\
Avocado pulp & $1.42^{*}$ & - & - & Wang et al., 2010 \\
Avocado peel & $\sim 8.9^{*}$ & - & - & Someyaa et al., 2002 \\
Banana pulp & 2.32 & - & - & Someyaa et al., 2002 \\
Banana peel & 9.07 & - & - & Li et al., 2006 \\
Pomegranate peel & 249.9 & - & - & Li et al., 2006 \\
Pomegranate pulp & 24.4 & & &
\end{tabular}




\subsection{Phenolic compound profile}

Characterization of phenolic compounds was performed by HPLC-DAD. The peak identities of the phenolic compounds were determined by comparison of corrected retention times, UV spectra from PDA and spiking samples with 16 commercial standards (Table 3 ).

The leaves extract of Myrciaria sp. revealed nine different compounds in the free and bound phenolics extraction, for the peak identification, see Table 3 and Figure 1. Seven of the ten compounds were identified in the extraction for free phenolics: 2,4 dihydroxybenzoic, vanillin, $p$-coumaric, ferulic, sinapinic acids and rutin in both extracts and the EtOH extract also revealed epicatechin. Even though, the extraction for bound phenolics showed more two different compounds: transcaffeic and myricetin (EtOH) (Table 3).

The phenolic profile of Myrciaria sp. leaves extracts was similar to those found in other studies with fruits, considering that there are no previous studies relating the phenolic profile of Myrciaria sp. leaves. Phenolic acids including $p$ coumaric, sinapinic and ferulic are secondary aromatic plant products suggested to possess many physiological and pharmacological functions. They have been anteriorly found in several fruits such as banana, persimmon, durian, grape, strawberry, apple pulp, kiwi, mangosteen, pomelo, grapefruit and lemon (Parka et al., 2015), and in both analyzed extracts, they were the most abundant compounds identified, presenting the highest peaks (Figure 1). Czyżewska et al. (2016) showed that $p$-coumaric and ferulic acids were able to induce cytotoxicity on human tongue carcinoma cells (Czyżewska et al., 2016).

In addition, the protection of vascular function by sinapinic acid was examined on experimental hypertensive animal model and the protection was attributed to antioxidant potential and attenuating fibrosis capacity of the compound (Silambarasan et al., 2014). Vanillin also presented a great peak in both extracts (Figure 1), the compound is a oxidized form of vanillic acid, and was recently demonstrated that provides neuroprotection through its potential pharmacological functions including antioxidant, anti-inflammatory, mitochondrial protective and anti-apoptotic properties (Dhanalakshmi et al., 2016).

Table 3

Retention time (Rt), total commercial standards utilized and identification of free and bound phenolic compounds in EtOH and MeOH extracts of Myrciaria sp. leaves by HPLC-DAD analysis

\begin{tabular}{|c|c|c|c|c|c|c|}
\hline \multirow[b]{2}{*}{ Phenolic Compound } & \multicolumn{3}{|c|}{ Free phenolics } & \multicolumn{3}{|c|}{ Bound phenolics } \\
\hline & $\mathrm{EtOH}$ & $\mathrm{MeOH}$ & $\begin{array}{c}\mathrm{Rt} \\
(\mathrm{min})\end{array}$ & $\mathrm{EtOH}$ & $\mathrm{MeOH}$ & $\begin{array}{c}\mathrm{Rt} \\
(\mathrm{min})\end{array}$ \\
\hline Gallic acid & - & - & - & - & - & - \\
\hline Pyrogallol & - & - & - & - & - & - \\
\hline 3,4-dihydroxyphenylacetic acid & - & - & - & - & - & - \\
\hline Catechin & - & - & - & - & - & - \\
\hline 4-hydroxybenzoic & - & - & - & - & - & - \\
\hline Epicatechin & $\checkmark$ & - & 10.51 & - & - & - \\
\hline Trans-caffeic & - & - & - & $\checkmark$ & $\checkmark$ & 9.94 \\
\hline Vanillic acid & - & - & - & - & - & - \\
\hline 2,4 dihydroxybenzoic & $\checkmark$ & $\checkmark$ & 10.4 & - & - & - \\
\hline Vanillin & $\checkmark$ & $\checkmark$ & 12.42 & - & - & - \\
\hline$p$-coumaric & $\checkmark$ & $\checkmark$ & 12.1 & $\checkmark$ & $\checkmark$ & 11.95 \\
\hline Ferulic & $\checkmark$ & $\checkmark$ & 12.28 & $\checkmark$ & $\checkmark$ & 12.43 \\
\hline Sinapinic & $\checkmark$ & $\checkmark$ & 12.34 & $\checkmark$ & $\checkmark$ & 12.52 \\
\hline Rutin & $\checkmark$ & $\checkmark$ & 13.90 & - & - & - \\
\hline Myricetin & - & - & - & $\checkmark$ & - & 1.42 \\
\hline 2-hydroxybenzoic acid & - & - & - & - & - & - \\
\hline
\end{tabular}



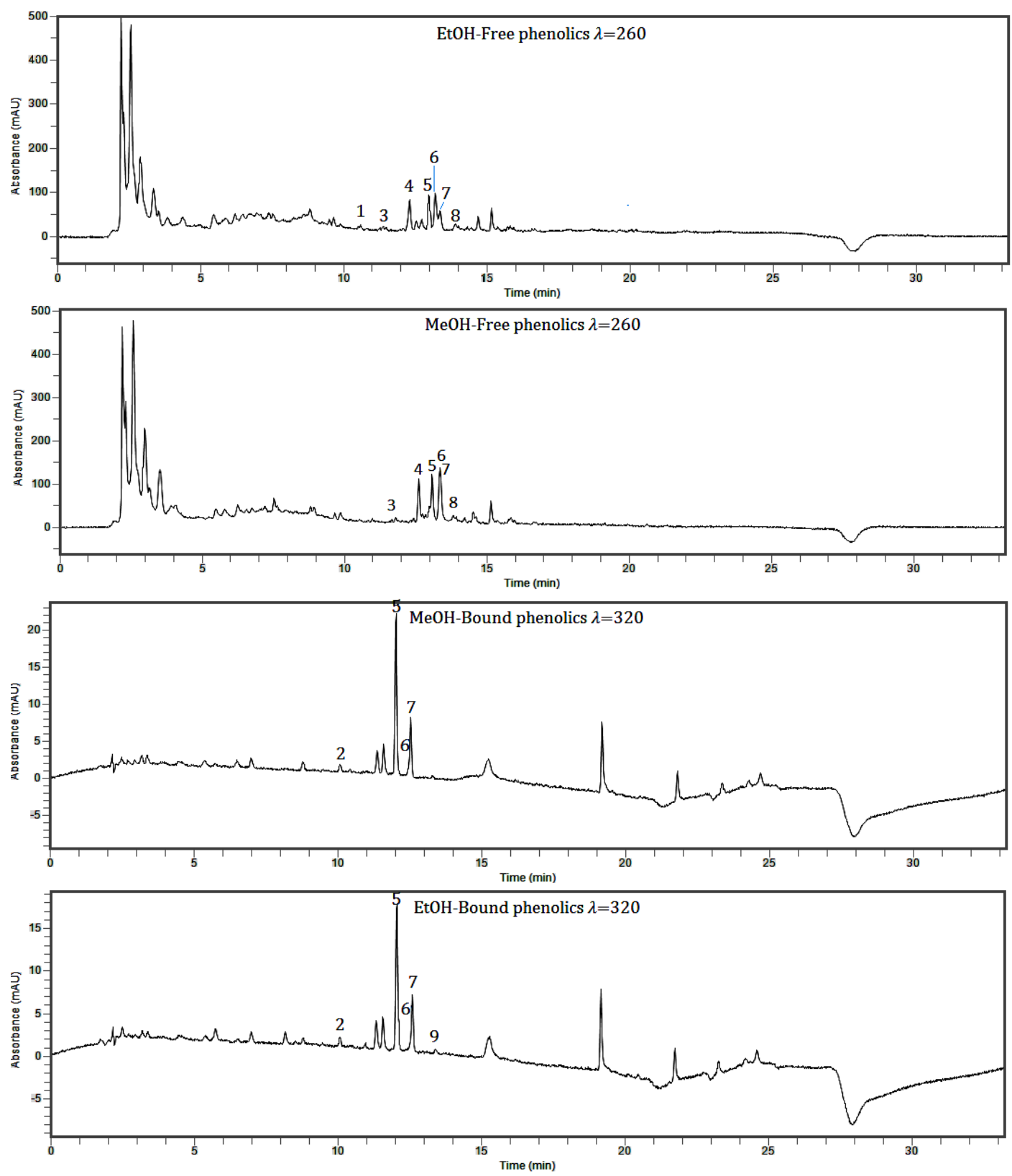

Figure 1. HPLC phenolic profile of the EtOH and $\mathrm{MeOH}$ extracts obtained from the leaves of Myrciaria sp., recorded at wavelengths of maximum absorption in visible region $(\lambda)$. Epicathequin (1), trans-caffeic (2), 2,4-dihydroxybenzoic acid (3), vanillin (4), $p$-coumaric acid (5), ferulic acid (6), sinapinic acid (7), rutin (8) and miricetin (9).

The phenolic compound profile of the extracts might influence not only its antioxidant capacity as widely described (Parka et al., 2015), but other biological functions as mentioned above.

In addition, the diversity of compounds founded and the amount of peaks not identified yet, gives us a background of a potential plant matrix to further investigate its characteristics in order to develop a nutraceutical agent rich in natural compounds.

\section{Conclusions}

The high antioxidant activity of $\mathrm{MeOH}$ and $\mathrm{EtOH}$ extracts appeared to be attributed to 
the high phenolics content and to the diverse phenolic profile of the Myrciaria sp. leaves. We consider that these extracts deserve more intensive study, including identification of all the peaks founded and its quantifications. Characterize the antioxidant composition and bioavailability to explore the possibility of developing a nutraceutical agent rich in natural antioxidants. In addition, investigate if the foliar extracts composition has some variation within seasons and environmental variables. Besides, considering that plants matter are not consumed and rarely approached, the high amount of bioactive compounds presented in these non-edible parts could be used for different purposes in the food industry such as enrichment or development of new products.

\section{Acknowledgments}

The authors acknowledge the financial support from FAPERJ, CNPq and CAPES (Brazil), as well as the assistance of the technician Henrique Abreu.

\section{References}

Arbos, K.A.; Stevani, P.C.; Castanha, R.F. 2013. Atividade antimicrobiana, antioxidante e teor de compostos fenólicos em casca e amêndoa de frutos de manga. Rev. Ceres, Viçosa, 60(2): 161-165.

Borges, L.L.; Conceição, E.C.; Silveira, D. 2014. Active compounds and medicinal properties of Myrciaria genus. Food Chem. 153: 224-33.

Brand-Williams, W.; Cuvelier, M.E.; Berset, C. 1995. Use of a free radical method to evaluate antioxidant activity. Food Science and Technology 28(1): 25-30.

Czyżewska, U.; Siemionow, K.; Zaręba, I.; Miltyk, W. 2016. Proapoptotic activity of propolis and their components on human tongue squamous cell carcinoma cell line (CAL-27). PLoS One 11:6, e0157091.

Dhanalakshmi, C.; Janakiraman, U.; Manivasagam, T.; Thenmozhi, A.; Essa, M.M.; Kalandar, A.; Khan, M.A.; Guillemin, G.J. 2016. Vanillin attenuated behavioural impairments, neurochemical deficts, oxidative stress and apoptosis against rotenone induced rat model of parkinson's disease. Neurochem Res (In press)

Diniz, D.N.; Macêdo-Costa, M.R.; Pereira, M.S.V.; Pereira, J.V.; Higino, J.S. 2010. Efeito antifúngico in vitro do extrato da folha e do caule de Myrciaria cauliflora Berg. sobre microrganismos orais. Rev Odontol UNESP 39(3): 151-156.

Duarte, A. R.; Santos, S.C.; Seraphinb, J.C.; Ferri, P.H. 2010. Environmental influence on phenols and essential oils of Myrciaria cauliflora leaves. J. Braz. Chem. Soc. 21(9): 1672-1680.

Einbond, L.S.; Reynertsona, K.A.; Luo, X.; Basileb, M.J.; Kennelly, E.J. 2004. Anthocyanin antioxidants from edible fruits. Food Chemistry 84: 23-28.

Gomes, S.; Torres, A.G. 2016. Optimized extraction of polyphenolic antioxidant compounds from Brazil nut (Bertholletia excelsa) cake and evaluation of the polyphenol profile by HPLC. J Sci Food Agric. 96(8): 2805-2814

Henriques, A.T.; Castro, C.M.; Gonçalves, E.D.; Corrêa, E.R.; Pizzoli, G.; Zuanazzi, J.A.S.; Antunes, L.E.C.; Raseira, M.d.C.B.; Apel, M.; Marin, R.; Limberger, R.; Trevisan, R.; Franzon, R.C. 2010. Espécies frutíferas nativas do Sul do Brasil. 124. Pelotas, RS: Empresa Brasileira de Pesquisa Agropecuária (Embrapa).

John, J.; Shahidi, F. 2010. Phenolic compounds and antioxidant activity of Brazil nut (Bertholletia excelsa). J Funct Foods 2(3): 196-209.

Li, Y.; Guo, C.; Yang, J.; Wei, J.; Xu, J.; Cheng, S. 2006. Evaluation of antioxidant properties of pomegranate peel extract in comparison with pomegranate pulp extract. Food Chemistry 96(2): 254-260.

Lucena, R.F.P.; Nascimento, V.T.; Araújo, E.d.L.; Albuquerque, U.P.d. 2008. Local uses of native plants in an area of Caatinga vegetation (Pernambuco, NE Brazil). Ethnobotany Research \& Applications 6: 3-14.

Morales, P.; Barros, L.; Dias, M.I.; Santos-Buelga, C.; Ferreira, I.C.; Ramirez-Asquieri, E.; Berrios, J.e.J. 2016. Non-fermented and fermented jabuticaba (Myrciaria cauliflora Mart.) pomaces as valuable sources of functional ingredients.' Food Chem. 208: 220-227.

Parka, Y.S.; Cvikrová, M.; Martincová, O.; Ham, K.S.; Kang, S.G.; Park, Y. K.; Namiesnik, J., Rombolàe, A.D.; Jastrzebskif, Z.; Gorinstein, S. 2015. In vitro antioxidative and binding properties of phenolics in traditional, citrus and exotic fruits. Food Research International 74: 37-47.

Silambarasan, T.; Manivannan, J.; Krishna-Priya, M.; Suganya, N.; Chatterjee, S.; Raja, B. 2014. Sinapic acid prevents hypertension and cardiovascular remodeling in pharmacological model of nitric oxide inhibited rats. PLoS One 9:12, e115682.

Singleton, V.L.; Orthofer, R.; Lammela-Ranvenson, R.M. 1999. Analysis of total phenols and other oxidation substrates and antioxidants by means of FolinCiocalteu reagent. Methods Enzymol 299: 152-178.

Someyaa, S.; Yoshikib, Y.; Okubob, K. 2002. Antioxidant compounds from bananas (Musa cavendish). Food Chemistry 79(3): 351-354

Souza-Moreira, T.M.; Moreira, R.R.D.; Sacramento, L.V.S.; Pietro, R.C.L.R. 2008. Histochemical, phytochemical and biological screening of Plinia cauliflora (DC.) Kausel, Myrtaceae, leaves Plinia cauliflora (DC.) Kausel, Myrtaceae, leave. Brazilian Journal of Pharmacognosy 20(1): 48-53.

Wang, W.; Bostic, T.R.; Gu, L. 2010. Antioxidant capacities, procyanidins and pigments in avocados of different strains and cultivars. Food Chemistry 122(4): 1193-1198 